\title{
An Acute Case of Herpes Zoster Ophthalmicus with Ophthalmoplegia
}

\author{
Wasim Hakim, ${ }^{1}$ Rosalie Sherman, ${ }^{1}$ Tamer Rezk, ${ }^{1}$ and Kanwar Pannu ${ }^{2}$ \\ ${ }^{1}$ The Postgraduate Education Centre, Basildon University Hospital, Essex SS16 5NL, UK \\ ${ }^{2}$ Department of Respiratory Medicine, The London Chest Hospital, Bonner Road, London E2 9JX, UK
}

Correspondence should be addressed to Wasim Hakim, wasimhakim@doctors.org.uk

Received 6 February 2012; Accepted 5 March 2012

Academic Editors: D. Callanan, A. Ferreras, and M. B. Parodi

Copyright (C 2012 Wasim Hakim et al. This is an open access article distributed under the Creative Commons Attribution License, which permits unrestricted use, distribution, and reproduction in any medium, provided the original work is properly cited.

Herpes zoster ophthalmicus (HZO) with oculomotor nerve involvement is rare, even rarer as an acute presentation rather than sequelae of HZO. In this paper we present a case of cutaneous HZO in which our patient's initial presentation was one of complete ophthalmoplegia.

\section{Introduction}

Herpes zoster (or shingles) refers to a typically vesicular rash caused by reactivation of the latent varicella zoster virus (chickenpox) from the dorsal root ganglia neurons. It usually presents in thoracic or cranial dermatoms. The lifetime risk of herpes zoster is estimated to be $10 \%$ to $20 \%$, but in patients over the age of 80 years this risk rises to $50 \%$. Reactivation can occur for a number of different reasons including trauma, ageing, or immune deficiency [1].

$\mathrm{HZO}$ is a rare form of shingles, reported in $15-25 \%$ of cases [2], that presents with a rash in the distribution of the trigeminal nerve dermatomes (mainly ophthalmic and maxillary divisions). It is often reported to be associated with a variety of complications, including episcleritis, keratitis, glaucoma, and cataracts [1], but there are very few reports of complete ophthalmoplegia being one of those.

\section{Case Presentation}

An 87-year-old lady who lives alone presented to the medical admissions unit with an inability to open her right eye. She has a past history of mild dementia and depression and was previous to this otherwise fit and well. She describes a 6day history of blister formation surrounding the eye that extends to her right forehead and scalp. Her family noticed her eye was becoming increasingly droopy, red, and swollen culminating in it being permanently shut for twenty-four hours prior to admission. This visual impairment was most likely responsible for her falling before attending hospital, during which she sustained a left elbow laceration. Of note, she had been started two days previously on flucloxacillin and phenoxymethylpenicillin by her general practitioner.

On examination she had a vesicular rash covering her right scalp, forehead, eye, and upper cheek. It was erythematous, swollen, and tender. She had a complete ophthalmoplegia, and her pupil was fixed and dilated. Her visual acuity in that eye was reduced to counting fingers. The remainder of her neurological and other systems examinations were normal. She was commenced on oral and topical acyclovir, dexamethasone, and cyclopentolate subsequent to ophthalmology review. There was no evidence of vasculitis on slitlamp examination (see Figures 1 and 2).

The vesicular rash resolved some two weeks later after admission, and she was discharged. She had regained some of her eye movements partially but the ptosis remained.

\section{Discussion}

In the limited literature, that does report opthalmoplegia as part of the sequelae of $\mathrm{HZO}$, this has typically been described as a late complication, often up to 2 months after the initial herpetic rash [3] and is seen in only $11-29 \%$ of patients with HZO. However, in our case it has developed as part of 


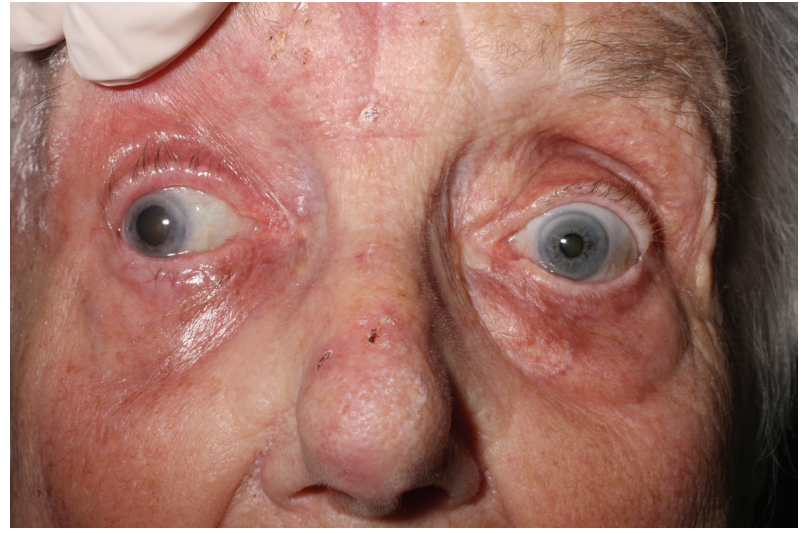

Figure 1: Oculomotor nerve palsy-pupil fixed and dilated in a position of lateral and downward gaze.

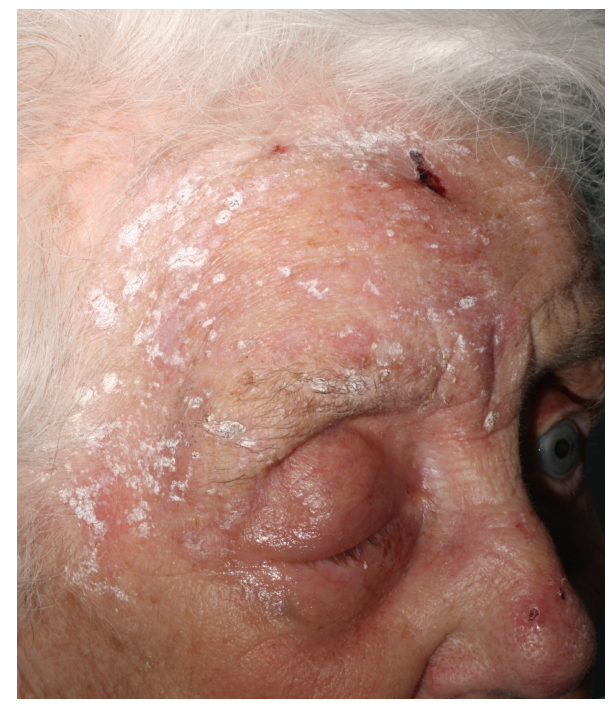

FIgURE 2: To show the rash in the distribution of the ophthalmic branch of the trigeminal nerve.

the acute viral infection. The most commonly affected nerve is the third cranial nerve and, less commonly, the fourth nerve [4]. With a third nerve palsy it has been reported as being partial or complete but there is always ptosis. Isolated ptosis and isolated paralysis of the pupil have also been seen [5]. In our case, there was third cranial nerve (oculomotor) palsy causing complete external ophthalmoplegia, with her pupil fixed and middilated.

Several hypotheses have been proposed for the mechanism behind which HZO can result in ophthalmoplegia [58] although it is most likely that there are many contributing factors. It is known that the reactivated virus causes inflammation of the axons that supply the dermatomes in question. Edgerton suggested that the inflammation of the trigeminal nerve could actually spread via the cavernous sinus to affect the oculomotor nerve [5]. In addition, Naumann et al. found chronic inflammatory cells suggesting an occlusive vasculitis [6]. Carrol thought that due to the onset and rate of recovery, this pathology would suggest a demyelinating disease, and
Lavin et al. were in agreement with this hypothesis based on autopsy reports $[7,8]$.

Diagnosis of this condition is essentially a clinical one based on history and examination findings. Once the diagnosis is made, it is reported that the earlier treatment is initiated, the better the prognosis is, preferably within 72 hours, although beneficial effects have been reported with treatment started as late as 7 days after onset [9]. Acyclovir, famciclovir or valacyclovir have all been used, and they act by resolving skin lesions, decreasing viral shedding and decreasing the risk of ocular involvement. Some report that famciclovir and valacyclovir are better at resolving pain associated with HZO than acyclovir [9]. In addition to the antivirals it is important to treat any further complications detected. For example, if keratitis or episcleritis has developed, then topical steroids can be used. The effectiveness of steroids and antivirals alone or in combination does not, however, appear to have been formally studied, and treatment options are limited partly due to the poorly defined mechanism of HZO.

The prognosis for full recovery after complete opthalmoplegia following HZO is good. In one literature review, of 16 total cases, 9 were followed up, and all of those cases showed significant improvement in symptoms after 2 months and almost complete resolution by 18 months [10].

\section{Conclusion}

Ophthalmoplegia is a rare complication of HZO. Furthermore, the cases in the literature describe it as relatively late sequelae, unlike the acute presentation we have reported.

\section{Abbreviation}

HZO: Herpes zoster ophthalmicus.

\section{Consent}

Written informed consent was obtained from the patient for publication of this case report and accompanying images.

\section{Authors' Contribution}

W. Hakim, R. Sherman, T. Rezk and K. Pannu were all involved in the care of the patient on the ward and contributed to writing up the case and performing a literature review. All authors read and approved the final paper.

\section{Conflict of Interests}

The authors declare that they have no conflict of interestes.

\section{Disclosure}

All doctors were at Basildon Univeristy Hospital at the time when this case presented; however the instiutions listed above show their current place of work. 


\section{References}

[1] R. J. Marsh, "Herpes zoster ophthalmicus," Journal of the Royal Society of Medicine, vol. 90, no. 12, pp. 670-674, 1997.

[2] D. Pavan-Langston, "Clinical manifestation and therapy of herpes zoster ophthalmicus," Comprehensive Ophthalmology Update, vol. 3, pp. 217-225, 2002.

[3] A. Chang-Godinich, A. G. Lee, P. W. Brazis, T. J. Liesegang, and D. B. Jones, "Complete ophthalmoplegia after zoster ophthalmicus," Journal of Neuro-Ophthalmology, vol. 17, no. 4, pp. 262-265, 1997.

[4] T. DeLengocky and C. M. Bui, "Complete ophthalmoplegia with pupillary involvement as an initial clinical presentation of herpes zoster ophthalmicus," Journal of the American Osteopathic Association, vol. 108, no. 10, pp. 615-621, 2008.

[5] A. E. Edgerton, "Herpes Zoster ophthalmicus: report of cases and a review of the literature," Transactions of the American Ophthalmological Society, vol. 40, pp. 390-439, 1942.

[6] G. Naumann, M. Gass, and R. L. Font, "Histopathology of herpes zoster ophthalmicus," American Journal of Ophthalmology, vol. 65, no. 4, pp. 533-541, 1968.

[7] W. M. Carroll and F. L. Mastaglia, "Optic neuropathy and ophthalmoplegia in herpes zoster oticus," Neurology, vol. 29, no. 5, pp. 726-729, 1979.

[8] P. J. M. Lavin, S. G. Younkin, and S. H. Kori, "The pathology of ophthalmoplegia in herpes zoster ophthalmicus," NeuroOphthalmology, vol. 4, no. 2, pp. 75-80, 1984.

[9] D. Pavan-Langston, "Herpes Zoster. Antivirals and pain management," Ophthalmology, vol. 115, supplement 2, pp. S13-S20, 2008.

[10] A. Chang-Godinich, A. G. Lee, P. W. Brazis, T. J. Liesegang, and D. B. Jones, "Complete ophthalmoplegia after zoster ophthalmicus," Journal of Neuro-Ophthalmology, vol. 17, no. 4, pp. 262-265, 1997. 


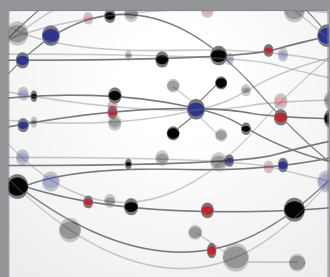

The Scientific World Journal
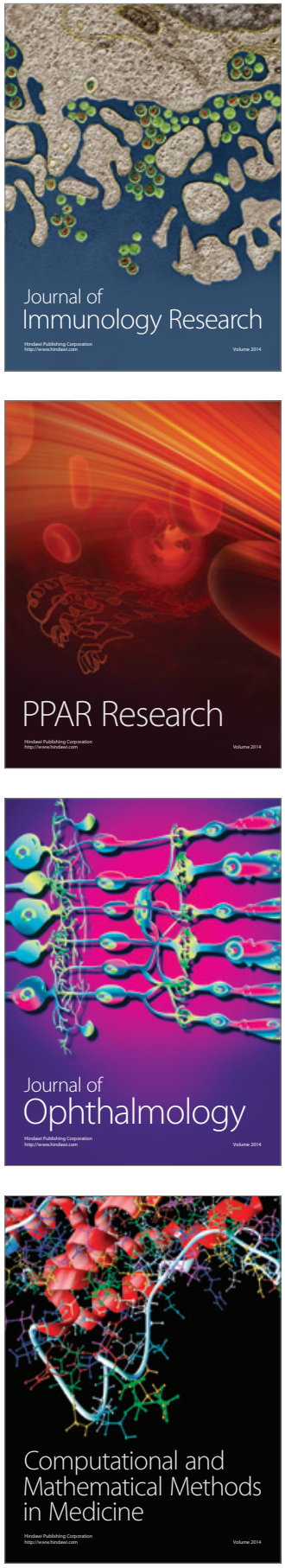

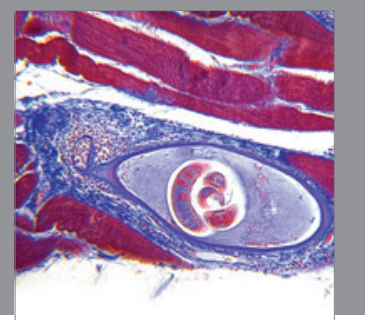

Gastroenterology

Research and Practice
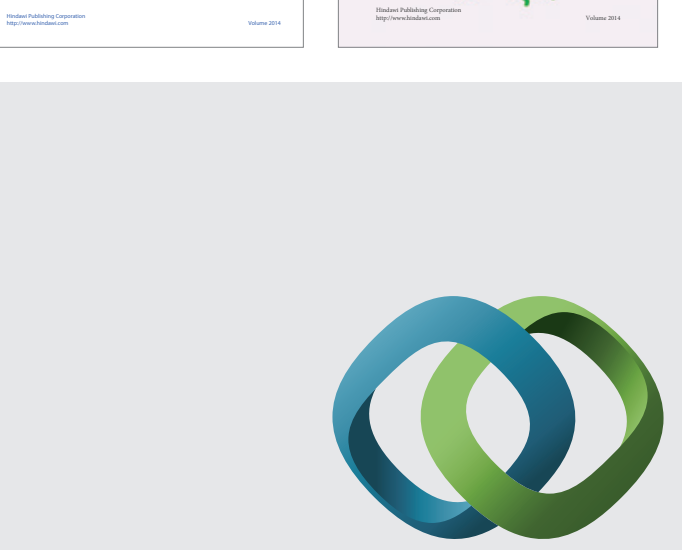

\section{Hindawi}

Submit your manuscripts at

http://www.hindawi.com
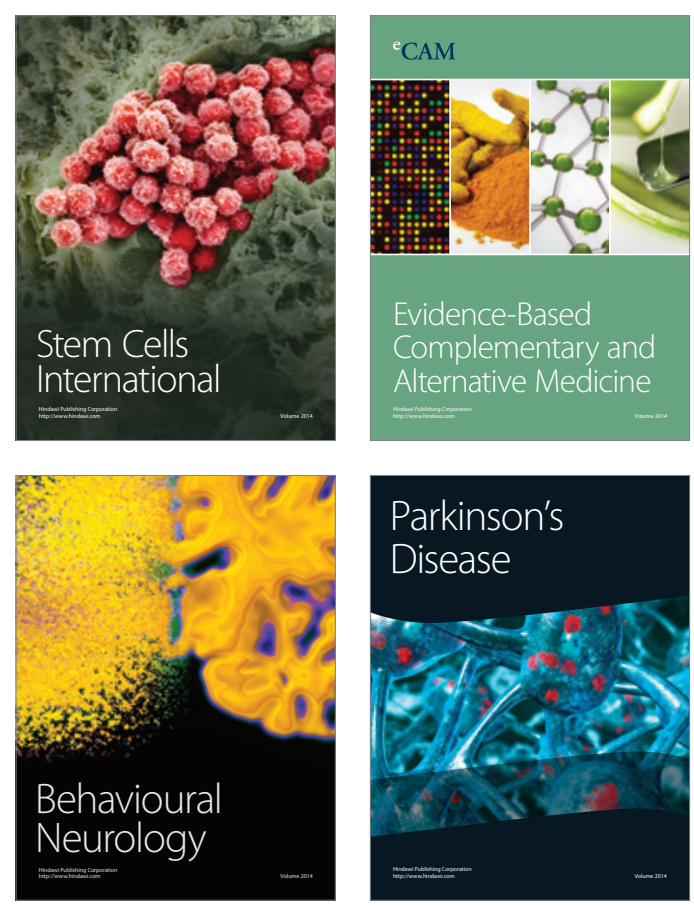

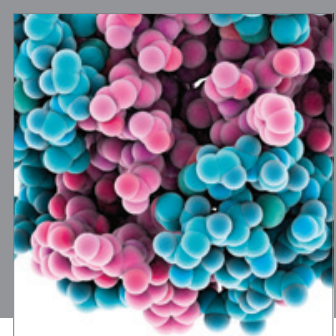

Journal of
Diabetes Research

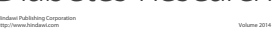

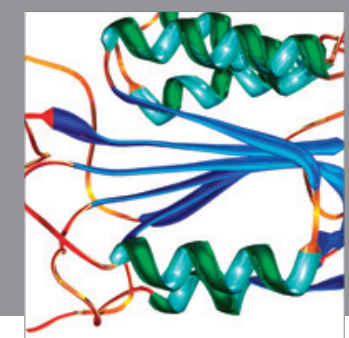

Disease Markers
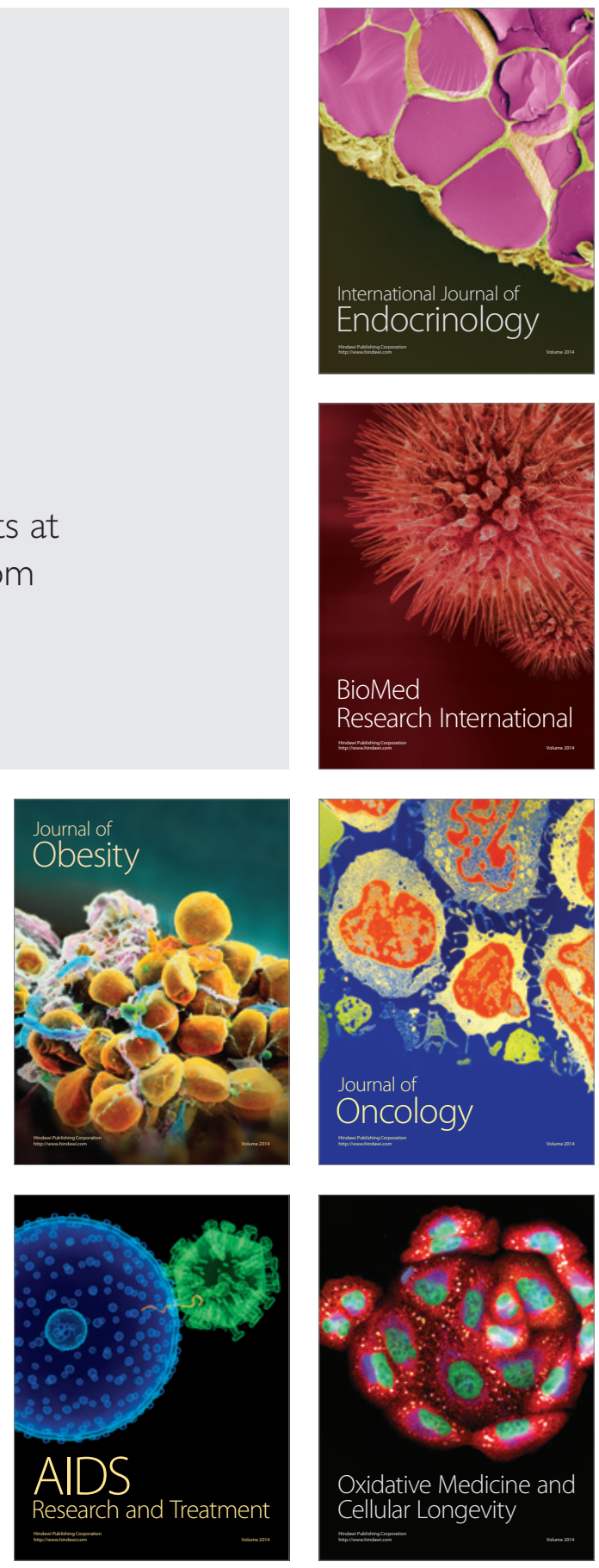